\section{REHABILITACION Y REFORMA ESTRUCTURAL DE EDIFICIOS ANTIGUOS}

\author{
Rafael Buzón, Ingeniero de Caminos \\ OTEP INTERNACIONAL \\ 105-2
}

\section{SINOPSIS}

Las Ordenanzas Municipales de la mayor parte de las ciudades exigen que se respeten las edificaciones con cierto carácter tradicional - histórico, rehabilitándolas o reconstruyéndolas, con la obligación de conservar integramente las fachadas en su mismo aspecto arquitectónico.

Un porcentaje importante del volumen futuro de construcción estará dirigido a estos edificios.

\section{Barrios enteros edificados en una misma época} con características constructivas similares, se encuentran en igual grado de deterioro o envejecimiento por el transcurso de los años, con un estado resistente precario, precisando de una pronta rehabilitación, si se quiere evitar el desalojo masivo y la pérdida irreversible de los inmuebles.

Se hace preciso conocer la técnica utilizada, el comportamiento de los materiales, los daños más frecuentes, por vicio o envejecimiento y la práctica de reparación eficaz para abordar este campo olvidado de la construcción.

\section{ORDENAMIENTO ESTRUCTURAL}

Está basado en muras de carga de fábrica de ladrillo o en paredes resistentes compuestas por entramados de madera y relleno de materiales diversos que pueden ser: cascotes, ladrillos o yesones, utilizando mortero de cal, bastardo o de cemento.

El forjado compuesto por viguería de madera, con entrevigado de rasilla o rellenos de material heterogéneo, o por viguería metálica, acompañada de entrevigado de tableros de rasilla o bloques huecos de cerámica.

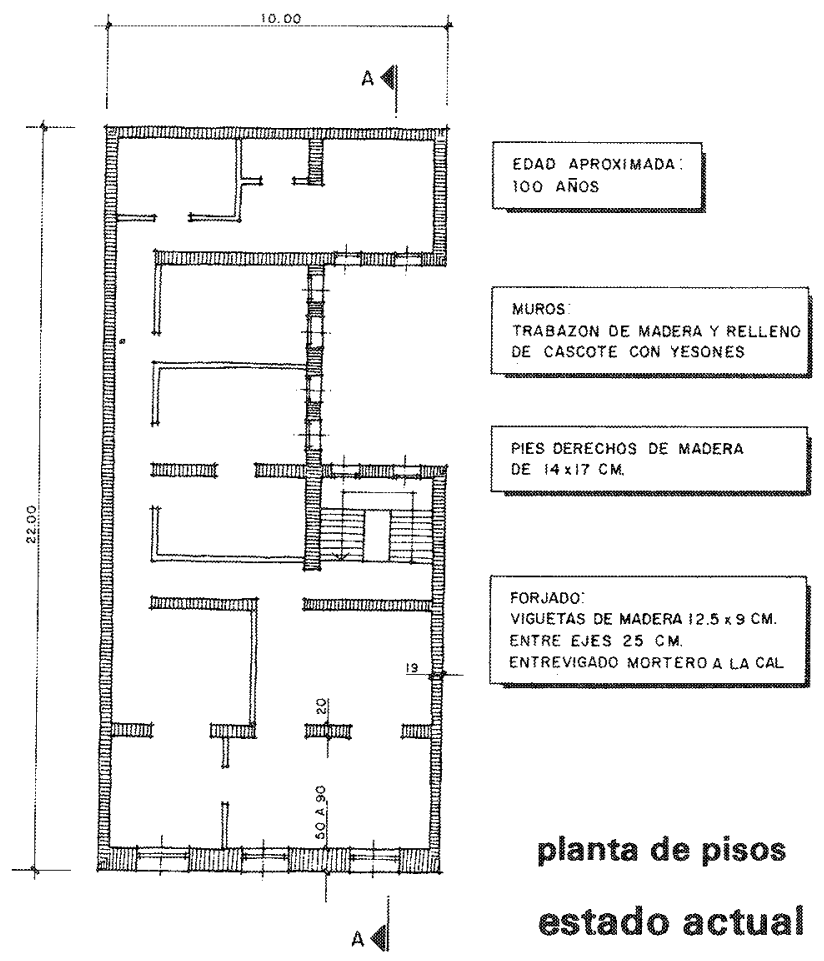

Las cubiertas, por lo general, son inclinadas, formadas por vigas y entablonado de madera. Recientemente se utiliza forjado horizontal.

Los materiales utilizados son indicativos de la época en que se construyó, definiendo también la edad y la medida de la altura de las plantas.

Signos característicos son: la robustez de las fachadas con respecto a los muros interiores, la mayor resistencia de los forjados en las zonas nobles, con respecto a las áreas destinadas a la servidumbre y la flexibilidad del conjunto.

\section{DAÑOS DEBIDOS A VICIOS O ENVEJECIMIENTO}

Las fachadas suelen ser sólidas, con espesores generosos. Se proyectaban así por encontrarse a la intemperie y por su mayor número de huecos. Son de fábrica de ladrillo macizo y revestidas.

Los muros interiores, generalmente de entramado de madera y rellenos diversos, al estar sometidos a mayores cargas y tensiones que las fachadas, suelen tener descensos acusados que motivan la inclinación del forjado de la primera crujía.

Los muros de patios son los más débiles por su menor espesor, profusión de huecos y estar expuestos a los perjuicios de las humedades de las bajantes y conduc- 


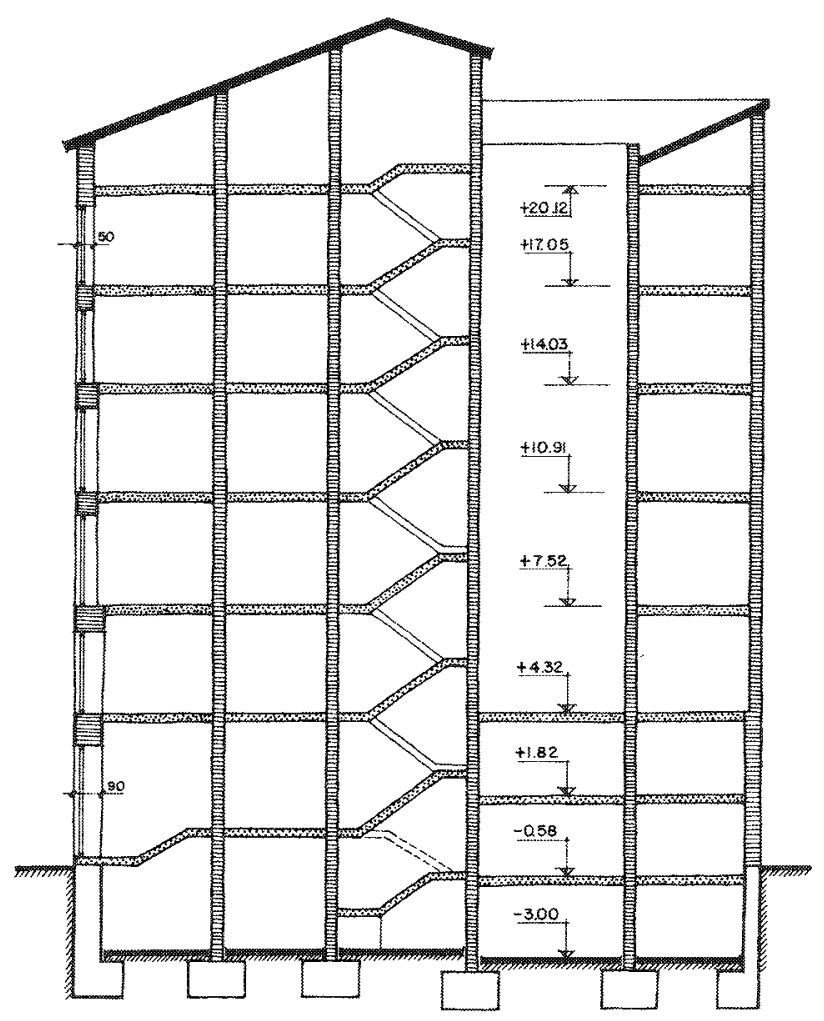

sección general

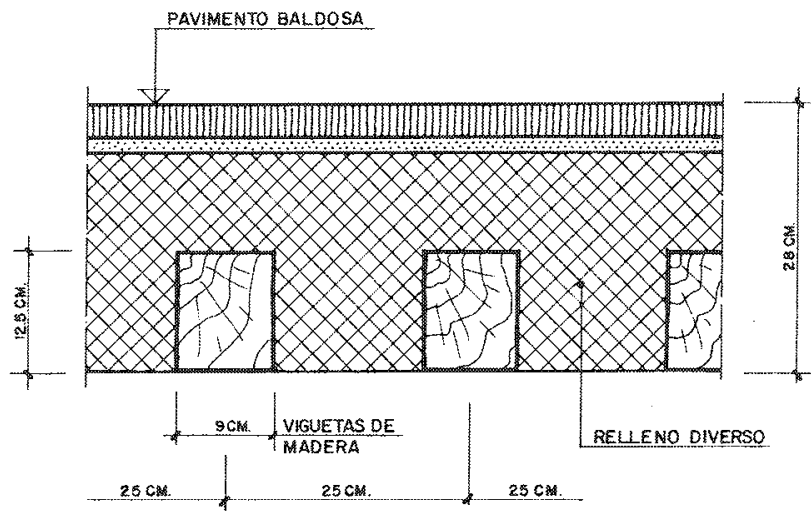

detalle de forjado

ciones de aguas, siendo, por lo general, la parte más deteriorada. Los pies derechos de madera suelen estar degradados en las bases de apoyo de la cimentación y en los lugares húmedos, con pérdida de su sección.

Los apoyos de la viguería de madera llegan a desaparecer en las áreas de servicios por las humedades. siendo un mal generalizado. La viguería en las dependencias nobles suele estar sana aunque acusa, bajo el pavimento, la concavidad producida. La viguería metálica se oxida en las dependencias de aseos $y$ cocinas.

La cubierta se deteriora en los puntos coincidentes con el contorno o junto a los linternones, lugares prom pensos a las humedades. Elementos ornamentales. como son las cornisas o salientes, suelen estar en situación de equilibrio inestable con el consiguiente peligro de desprendimientos.
La cimentación, realizada con cascotes, piedra o ladrillo - prácticamente sin concertar - es parca en sus dimensiones y no siempre se apoya en terreno firme, con la particularidad de que las tensiones al terreno son más elevadas en los muros interiores que en la tachada.

Las edificaciones antiguas sufrieron una convulsión perjudicial cuando fueron dotadas de las instalaciones que surgieron posteriormente, como pueden ser las de calefacción, termos, depósitos de agua, gas y ascensores.

\section{LA CALIDAD}

La calidad constructiva de los edificios antiguos seguía la línea de importancia y rango a que estuvieran destinados: es buena en los establecimientos oficiales, conventos, edificios señoriales, cuarteles, etc., y solamente mediana en las viviendas, empeorando la calidad de los materiales y ejecución en aquellas previstas para alquilar, especialmente desde principios del año 1900.

La calidad se muestra principalmente en los espesores de muros interiores y en la viguería de madera. En los muros interiores por la disminución de su espesor, haciendo trabajar a los pies derechos de madera a altas tensiones, y por el material de relleno del entramado, que puede pasar desde la fábrica de ladrillo al simple cascote sin seleccionar y precariamente concertado. En la viguería de madera por la heterogeneidad de sus secciones y separación, además del modo de realizar y recibir los apoyos en los muros, que en muchas ocasiones lo hacian con yeso.

En los últimos años, los edificios de muchas alturas, con muros de fábrica de ladrillo, supusieron un alarde sin límites en la disminución de los espesores, aplicando el medio pie como patrón único, acompañándolo de la supresión de una gran parte de los trabazones. Se abusaba de la ventaja de la mayor resis* tencia de las fábricas, por ser mejor el ladrillo y mortero, pero se olvidaban las circunstancias desfavo. rables, como eran el diseño arquitectónico de amplias aberturas en los huecos de ventanas o pasos, diafanidad de las habitaciones, la estabilidad por el incremento del número de alturas, las rozas en las paredes para el alojamiento de instalaciones, el ritmo acelerado en la ejecución sin tiempo para el fraguado del mortero, etc. Se interrumpió esta desafortunada construcción cuando aparecieron los primeros malos resultados propios de su endeblez.

\section{EL CALCULO}

El proyecto de las estructuras de edificios antiguos no era precedido de los cálculos de esfuerzos y tensiones de los materiales. Se hacian por comparación con otras edificaciones y de modo rutinario, lo cual era lógico por los pocos elementos que entraban en estas construcciones clásicas. Los muros tenían espesores superabundantes y estaban ensayados en la práctica. 
Las viguetas de madera se suministraban desde las aserrerías, de acuerdo con una tabulación que contemplaba la luz y su separación: los cargaderos eran lo más delicado de provectar y lo que más se discutía; la cimentación se realizaba continua $y$ de un ancho ligeramente superior a la base de los muros de carga, profundizando cuando se requería, hasta llegar al firme por medio de contrafuertes $y$ arcadas. Se temía poco conocimiento de las condiciones del terreno para cimentar y la labor práctica de asesoramiento la asumian, comúnmente, los poceros.

Aun en los ultimos tiempos, casi siempre se ha omitido el cálculo de los muros de fábrica de ladrillo de los edificios, bien por costumbre heredada o por falta de conocimiento, circunstancia que ha sido superada por la aparición de normas recientes. El cálculo es sencillo, pero tiene la pecullaridad de que precisa compaginar el saber teórico con el práctico para dominarlo.

\section{CAUSAS FRECUENTES DE DAÑOS}

La adición de plantas provoca el aplastamiento de los muros de carga, pues las fábricas resistentes con mortero de cal acusan los aumentos de tensiones. Los sintomas son el encaje de las puertas o ventanas.

El cambio del las cargas, como puede ser el pavimento o la sobrecarga, influye en la viguería. El cambio de uso implica deterioro y pérdida de resistencia.

Los cambios de tabiquerias producen alteraciones en las plantas superiores y su supresión puede ser peligrosa al disminuir la trabazón del conjunto.

La reforma o adaptación de los bajos para locales comerciales puede ser causa grave de un inicio de ruina del edificio, a no ser que se adopten medidas de precaución en la acomodación del edificio en esta clase de reformas y sean proyectadas y realizadas por personal con experiencia.

Existe controversia sobre la verticalidad de los muros resistentes de las fachadas, siendo opinión de algunos que se hacian con desplomes hacia el interior para contrarrestar los empujes de las cubiertas inclinadas y también como defensa ante el más fácil vuelco hacia el exterior. De las comprobaciones efectuadas y consultas a arquitectos de la generación pasada, no parece se adoptara esta precaución.

Efectivamente, en casos aislados aparecen desplomes hacia dentro, pero siempre han coincidido con ol descenso del muro paralelo, por lo que cabe pensar que esta sea la causa que fuerza la perdida de la verticalidad de la lachada.

\section{COLUMNAS DE HIERRO FUNDIDO}

Las columnas de hierro fundido o colado tienen presencia en la edificación antigua. Son elementos que transmiten las cargas verticales, estando formadas por fuste de sección en corona circular con bases

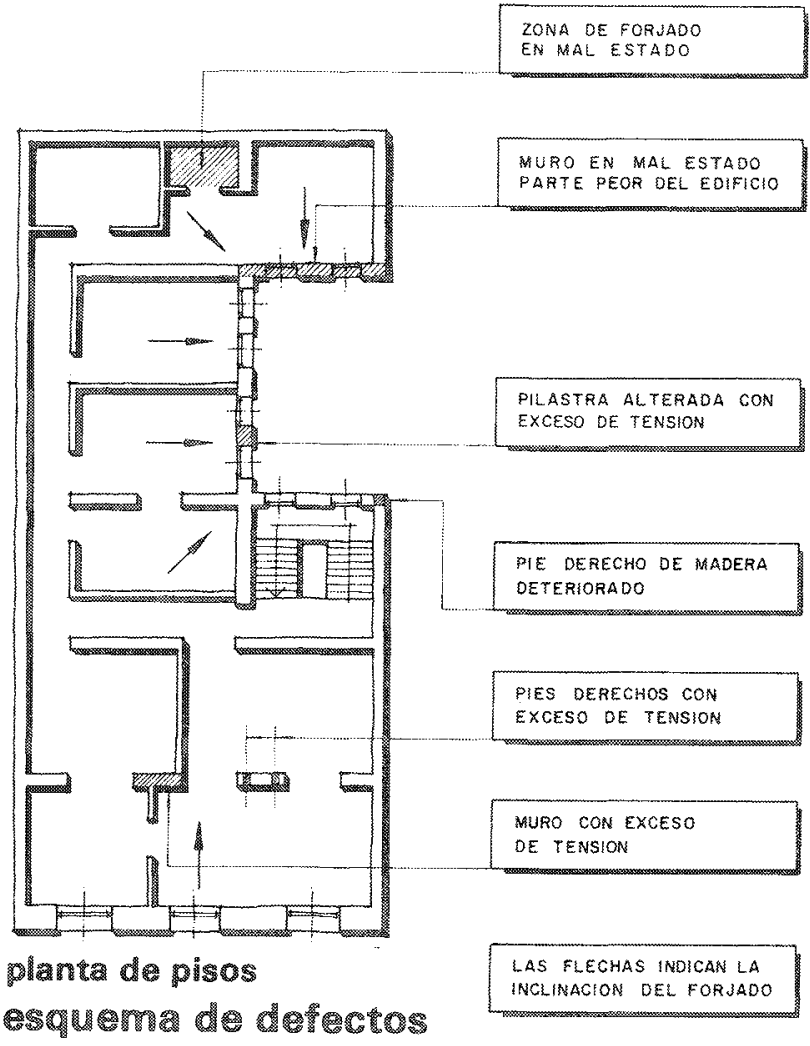

ensanchadas, pretendiendo, al mismo tiempo, ser motivo ornamental. En España empezó a utilizarse en la construcción a principios del año 1800, primera mente en los puentes y posteriormente en la edifica. ción y talleres industriales.

El componente se obtiene por fusión directa de los materiales de hierro, siendo la característica principal su alto contenido de carbono. El aspecto de la fractura es de grano gris, más o menos claro; su peso específico es de 7,2 como valor medio; no admite trabajo de forja y se deja trabajar bien al cepillo, lima y taladro. Son frecuentes los defectos interiores, grietas, sopla. duras, falta de homogeneidad en su constitución. factores que aconsejan ser prudentes en la estimación de las tensiones admisibles.

Las propiedades elásticas del hierro colado son de. ficientes y en sus fases de resistencia no presentan un limite de elasticidad definido. Los alargamientos, en parte proporcionales $y$ en parte elásticos a las tensio. nes, son sensibles a los esfruerzos repetitivos. La rotura se produce sin estricción, es decir, sin deformación plástica, con alargamiento muy pequeño, que no llega a alcanzar el $1,7 \%$. Como valor aproximado puede estimarse un coeficiente de elasticidad $E=920.000 \mathrm{~kg} / \mathrm{cm}^{2}$.

La rotura a la tracción suele estar comprendida entre 1.000 y $1.200 \mathrm{~kg} / \mathrm{cm}^{2}$, pero su fragilidad aconseja evitar en lo posible este estuerzo, que en todo caso no debería superar a los $200 \mathrm{~kg} / \mathrm{cm}^{2}$ en condiciones de servicio.

Bajo la acción de la compresión las deformaciones son también permanentes y elásticas. La resistencia a la 
rotura puede variar entre 6.000 y $8.000 \mathrm{~kg} / \mathrm{cm}^{2}$, pero sin embargo, por las razones de la incertidumbre respecto a la calidad del material, no conviene pasar de 600 a $900 \mathrm{~kg} / \mathrm{cm}^{2}$ la carga de servicio.

El mantenimiento de estas columnas de hierro representa un riesgo. Son altamente perjudiciales las vibraciones, choques, las excentricidades de cargas (como pueden ser las causadas por la deformación del propio edificio) o las sobrecargas alternadas bruscas, ya que el hierro colado acusa las acciones intermitentes y no admite apenas tracciones. El colapso se produce sin aviso.

Es aconsejable proceder a su sustitución o refuerzo, que puede ser metálico o bien mediante hormigonado, dejando la columna como núcleo inerte.

\section{PROVOCACION Y ACELERACION DEL GRADO DE RUINA}

Existen métodos usados, bien por ignorancia o intencionadamente, que pueden provocar y acelerar la ruina. Entre otros se apuntan los siguientes:

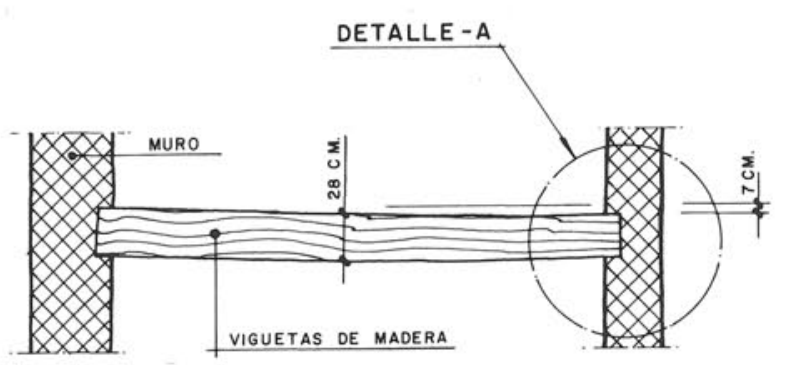

sección de forjado
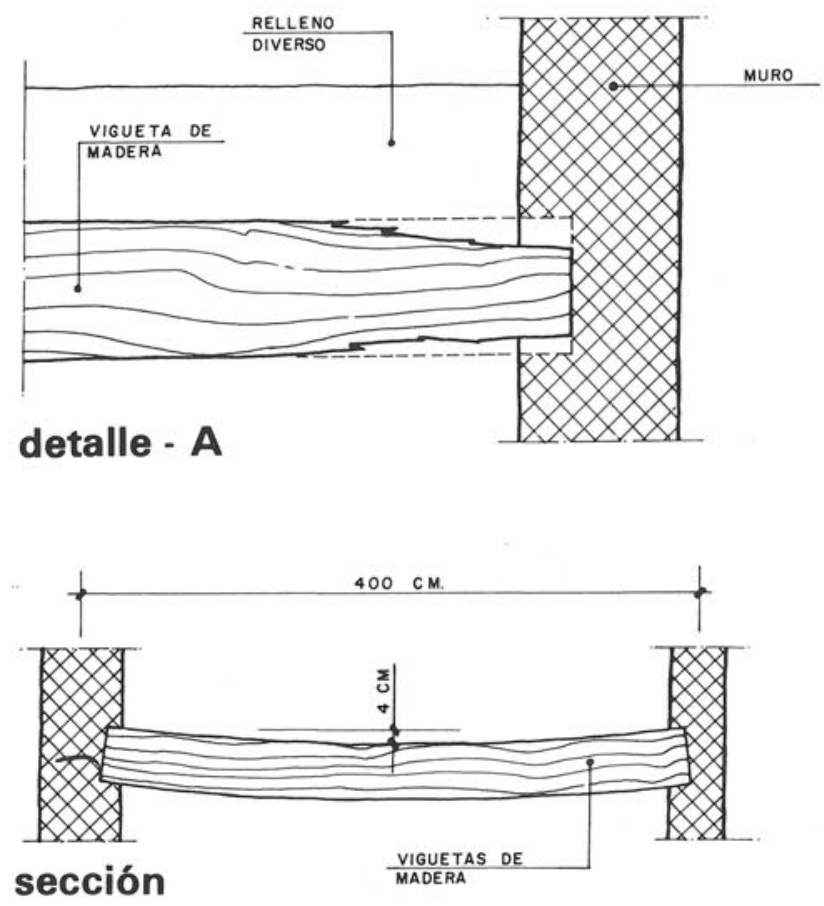

- El cegado de las bajantes en la parte inferior, provocando la entrada en carga y desbordamiento del agua.

- El llenado de agua de los conductos de calefacción, coindiciendo con pérdidas de las tuberías. İgualmente en los conductos de agua.

- La retirada de parte de la cobertura de tejas, dejando paso al interior de las aguas de lluvia.

- El tapar los sumideros de los patios, motivando el almacenamiento de aguas en los bajos.

- El dejar las ventanas abiertas facilitando las corrientes de aire.

- El exceso de carga en el forjado provocando su caída.

- La retirada de cercos en las ventanas exteriores, especialmente en patios.

- El incendio.

Las medidas de precaución que preserven de tales hechos, tienden a conservar el edificio en un largo plazo.

\section{REPARACIONES EN GENERAL}

La oportunidad al hacer una reparación es sumamente influyente en el grado de desperfectos futuros. Edificios potencialmente en ruinas dejarían de estarlo de realizarse consolidaciones eficaces y sencillas en un momento justo. La demora en acometerlas favorece la progresión exponencial de los daños, algunas veces irreversibles.

Las reparaciones deben ser precedidas de una revisión de las instalaciones que conduzcan agua.

Una cubierta bien dispuesta con garantía de impermeabilidad y una fontanería en debidas condiciones son los mejores medios de conservación.

En caso de necesidad de colocar un zunchado de atado sobre la fábrica, conviene que el hormigón tenga poca dosificación a efectos de disminuir la retracción y hacerlo más compatible con el material de la fábrica.

Las deformaciones no justifican siempre una consolidación ni son motivo de alarma. Las reparaciones más corrientes son:

\section{Reparación de muros interiores}

El descenso de muros no es de alarmar mientras se conserven en buen estado los pies derechos y no existan abombamientos superficiales. De aparecer oquedades o pérdidas de sección de la madera, la mejor solución es sanear y rellenar con hormigón de baja dosificación, o bien con ladrillo y mortero.

El material de relleno entre el entramado de madera suele tener poca cohesión, razón por la que existe en ambos paramentos un amplio espesor de guarnecido. De hacerse un saneado es conveniente sustituirlo por otro guarnecido con malla de alambre intercalada. 
En caso de que el muro entramado se encuentre en condiciones pésimas puede sustituirse por un entra. mado metálico, compuesto por columnas y vigas pareadas a ambos lados del mismo y debidamente empresilladas, de manera que sirva de apoyo a la viguería existente. El muro original puede retirarse posteriormente, lo que representa un alivio en el peso muerto.

\section{Reparación de muros de patio}

El mismo criterio anterior. En caso de gravedad puede optarse por un entramado metálico por el exterior sujeto a un enmarcado en los huecos de ventanas.

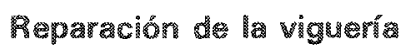

En las zonas de servicios lo mejor es la sustitución por vigueria metálica, dispuesta en el espacio del entrevigado. En ocasiones puede dejarse la viguería y entrevigado actual en evitación de mayores obras. La viguería sana debe mantenerse aunque la flecha sea acusada, lo que podría corregirse sustituyendo el entrevigado pesado y de gran espesor por otro más liviano, existiendo procedimientos sencillos para conferir al conjunto del forjado una mayor capacidad de carga. El pavimento clásico de terrazo o loseta es pesado y por lo general no apto, debiéndose tender a pavimento de madera rastrelado.

\section{Reforma de locales comercials}

Tienden a suprimir gran parte de la fachada y de los muros interiores para conseguir diafanidad. Los alardes no son recomendables. Las supresiones de fábrica pueden hacerse con elementos metálicos de gran rigidez, por un sistema que no precise de apuntalamientos, para conseguir deformaciones despreciables y no bruscas.

\section{RECOMENDACIONES EN LA SEGUPIDAD DEL RECONOCIMIENTO}

El reconocimiento de edificios por parte de los técnicos entraña algún riesgo, especialmente en aquellos que están sin habilitar durante algún tiempo, por lo que deben adoptarse cientas precauciones, como pueden ser:

- El reconocimiento debe hacerse como minimo por tres personas, situadas separadamente a cierta distancia, equipadas debidamente.

- La subida o bajada por escaleras hacerla por la parte interior, pegados a la caja de la escalera.

- Si el estado del forjado es precario pasar por el perimetro de las habitaciones.

- No forzar las puertas, evitando golpes para abrirlas, pues con frecuencia se desprenden los falsos techos. Cuidar no se produzcan corrientes que puedan cerrar y encajar las puertas.

- El paso por las cubientas inclinadas puede ser peligroso por la poca resistencia de los elementos que soportan las tejas, por lo que su reconocim miento debe estar precedido de las consiguientes medidas de seguridad.

\section{ORPAS CONSERVANDO LAS FACHADAS}

Es cada vez más frecuente la construcción de edificios en zonas del casco urbano antiguo donde es obligado mantener la fachada. Ello requiere utilizar una técnica encaminada a sostenerla en el periodo de derribo y durante la nueva construcción, así como su adaptación a dicha estructura.

Estas fachadas tienen peculiaridades constructivas comunes y materiales conocidos, variando la geometría de los huecos y espesores además de la ornamentación, lo que permite uniformar criterios para su sostenimiento. Son de fábrica de ladrillo macizo, recibido con mortero de cal o bastardo según la época, espesores superiores a $10 s 60 \mathrm{~cm}$ y que disminuyen con la altura. Su función es de cerramiento y de muro de carga. Las tensiones a compresión a que están sometidas las fábricas oscilan por lo general entre 5 y $10 \mathrm{~kg} / \mathrm{cm}^{2}$ una vez descontados los huecos.

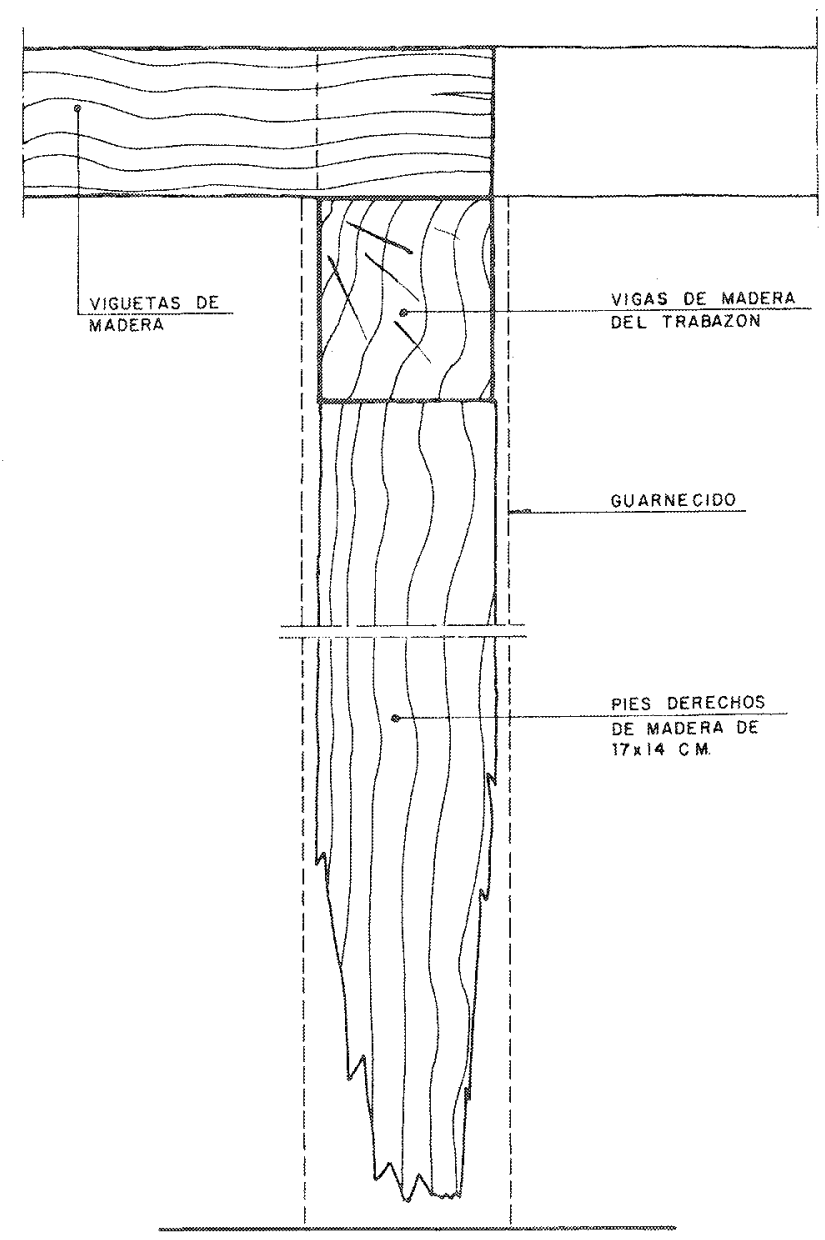

\section{pies derechos}




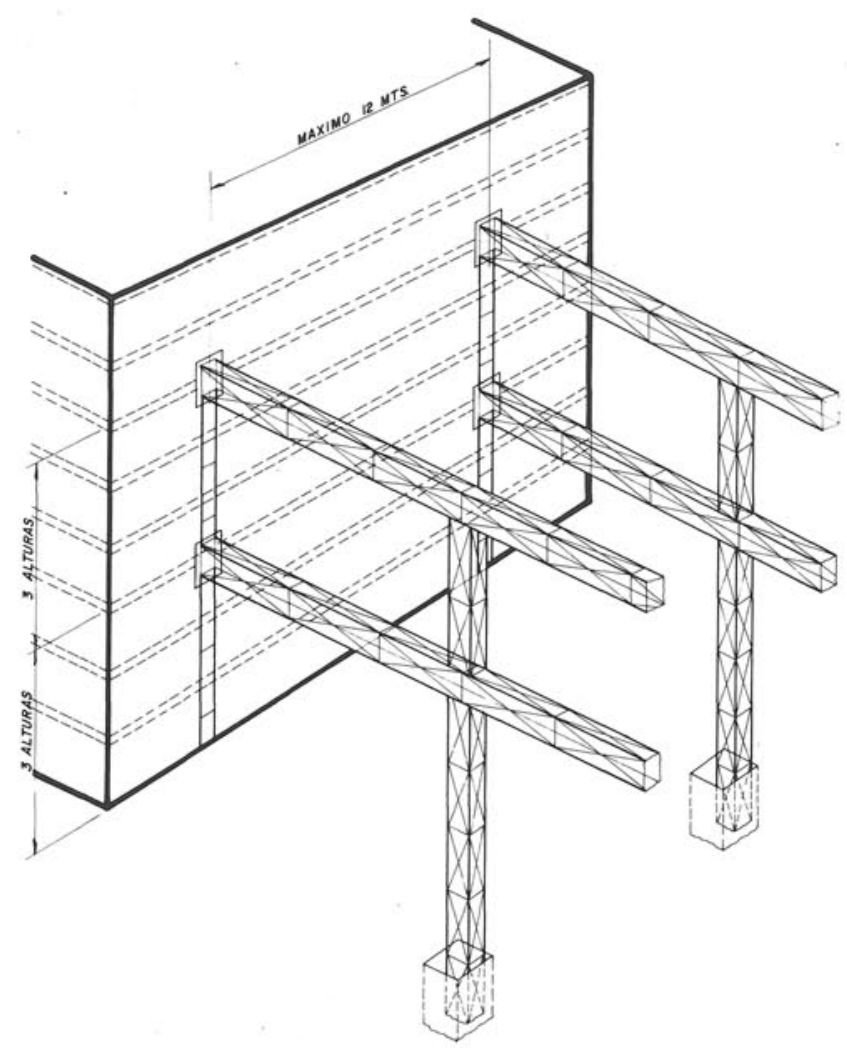

\section{apeos de edificios colindantes}

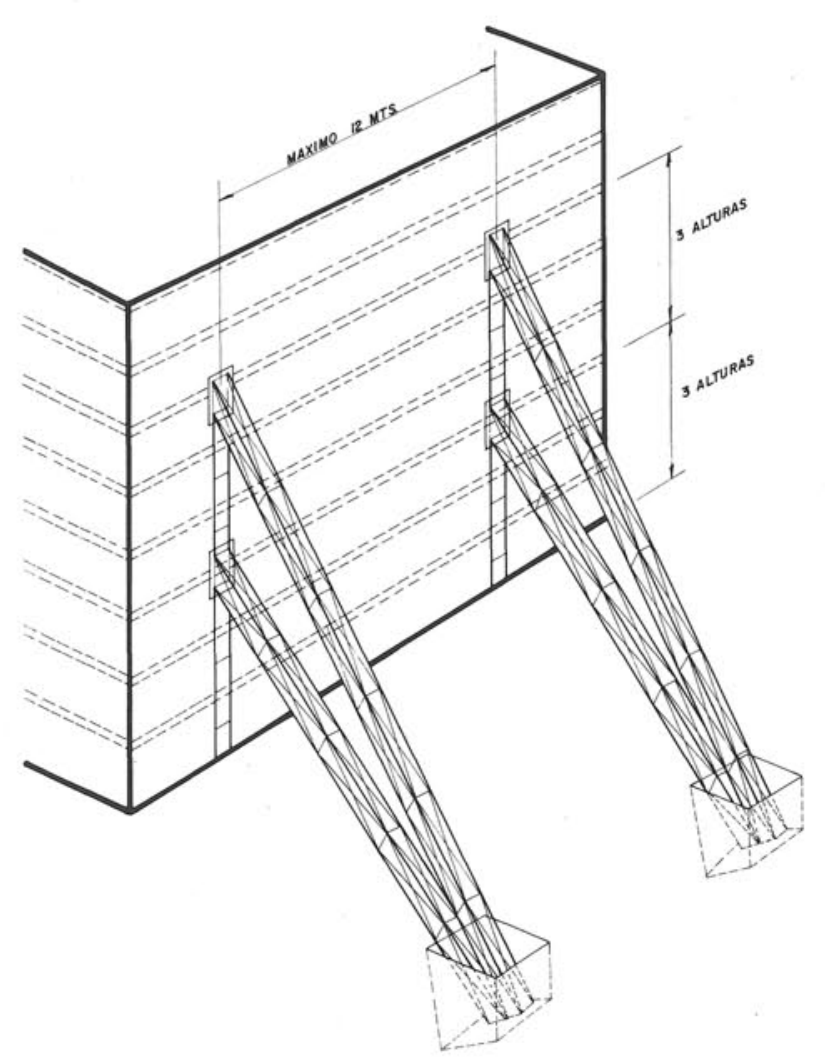

En el estudio del comportamiento de la fachada en su nuevo estado deben tenerse en cuenta dos factores principales:

- El primero, que el mortero se altera al quedar temporalmente la fábrica a la intemperie y también al descomprimirse por la retirada del peso de las plantas, produciéndose un estado distinto al original. Al retirar la viguería alojada en la fábrica en puntos próximos se produce en la línea una pérdida de sección con su consiguiente debilitamiento, formando una especie de rótula propensa a la rotura.

- El segundo factor es que la fachada en el caso de seguir actuando como muro resistente para los nuevos forjados precisa de una nueva cimentación o recalce para hacerla compatible con el resto del conjunto, mientas que si su función es solamente de cerramiento es probable sea suficiente la cimentación de origen.

Para el acceso al interior de los materiales, de la maquinaria de excavación o ejecución de las pantallas es necesario contar con el correspondiente gálibo de paso, que en ocasiones existe en lo que se denomina entrada de carruajes, pero que en otras se hace obligada su apertura mediante el oportuno pórtico.

La nueva estructura conviene sea metálica para facilidad del transporte y demás operaciones. También es conveniente que los elementos de sujeción de la fachada sean metálicos por sus excesivas longitudes y mejor manejo, siendo preferible no sean demasiado rígidos.

Una buena medida de precaución es colocar aspados de madera en todos los huecos y que los puntos de contacto entre las vigas de sostenimiento y la fachad́a sean también de madera.

La sujeción definitiva de la fachada a la nueva estructura conviene sea flexible para que permita el libre movimiento en sentido vertical de la fachada. Es prudente que los nuevos forjados incidan sobre una estructura adosada a la fachada con el fin de que ésta solamente tenga función de cerramiento.

El procedimiento para sostener la fachada es dependiente del diseño de la nueva obra, como pueden ser los sótanos y densidad de pilares, y también de la forma en planta de la propia fachada. Exponemos algunas soluciones adaptadas a casos corrientes.

\section{Sostenimiento con el propio edificio a derribar}

Consiste en iniciar el derribo parcial de los materiales no resistentes: la cobertura de tejas, tabiques secundarios, puertas, instalaciones, entrevigados, cielos rasos, etc. Se hace después la nueva cimentación y la estructura interior, sujetando a ella la fachada. A partir de este momento se procede a la total demolición del edificio antiguo, completando el entrevigado, la excavación del nuevo sótano si lo hubiere y los muros perimetrales. 
Esta solución es segura, pero compleja si la densidad de pilares es grande o bien si hay más de un sótano a realizar.

Sostenimiento con la crujía paralela del edificio a derribar

La solución es parecida a la anterior, con la ventaja de dejar espacio libre en el solar y con la desventaja de no tener acodalados los edificios medianeros.

\section{Sostenimiento de la fachada exenta}

La solución más conveniente es la de vigas de celosía horizontales apoyadas en los extremos de los muros del edificio a modo de contrafuertes y, si la luz es excesiva, colocando soportes intermedios. Según la forma en planta el procedimiento puede consistir en colocar codales horizontales en las esquinas. Otro procedimiento es el apeo inclinado, bien ocupando la calle, bien por el interior, bien de ambas formas.

\section{AUMENTO DE COSTE POR PROBLEMAS DE APEO O CONSERVACION DE LA FACHADA}

Efectivamente, el costo es mayor y variable según la repercusión de los condicionantes anteriormente comentados, pudiendo alcanzar un incremento entre el 10 y $50 \%$ del montante de la estructura.

Dado que en un edificio normal el presupuesto de la estructura con respecto al valor de la obra terminada

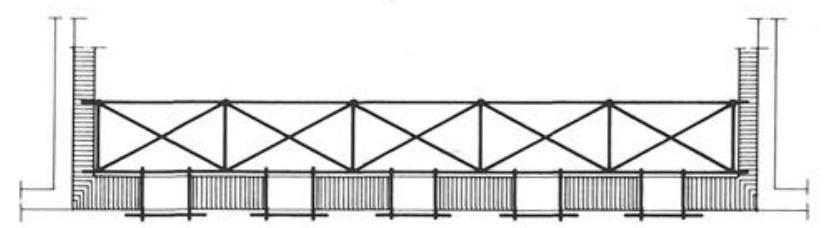

planta
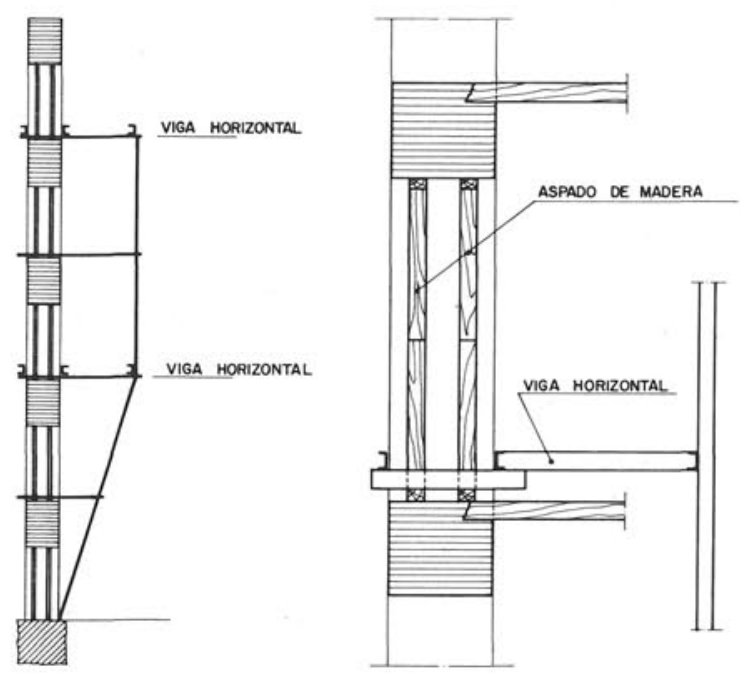

sección

detalle
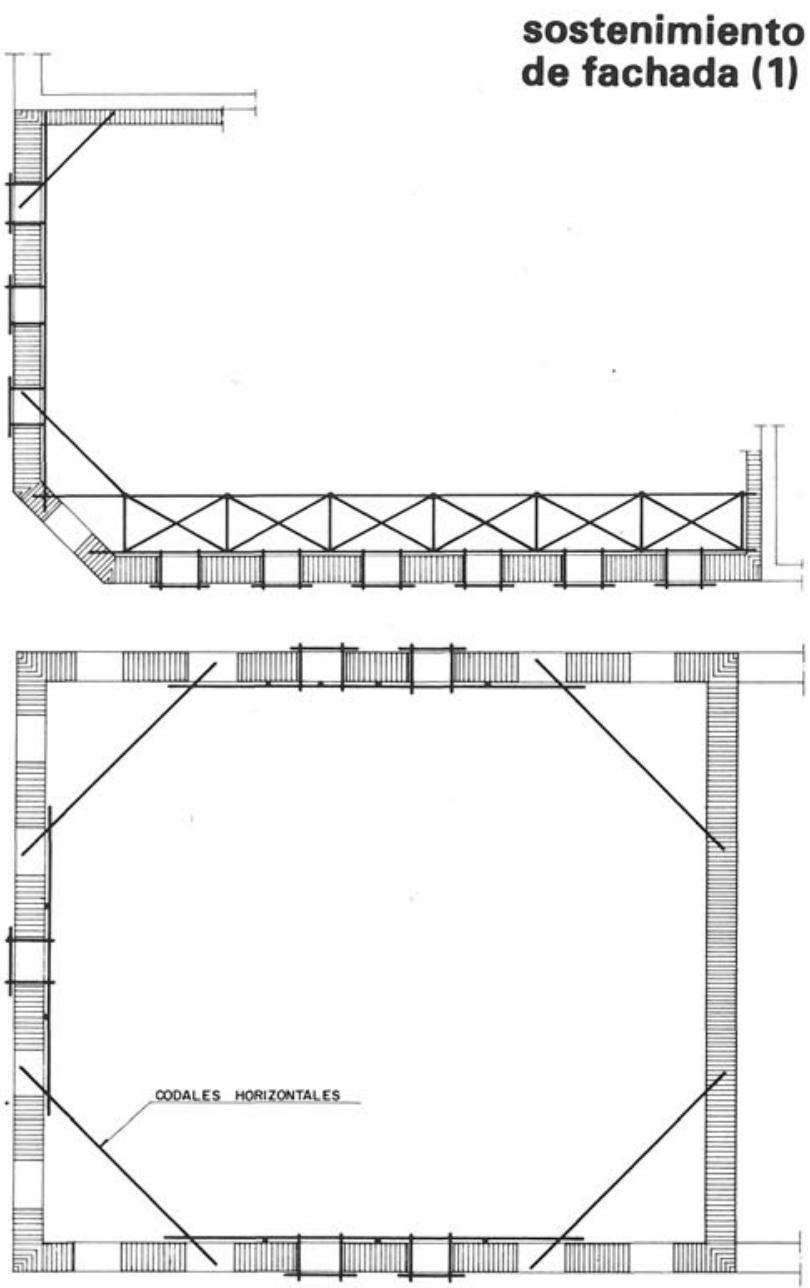

sostenimiento de fachada (2)

está en la proporción de 1 a 7, los problemas de apeo o conservación de la fachada no deben superar el $10 \%$ del valor total.

\section{APEOS DE EDIFICIOS ANTIGUOS, POR OBRAS DE CONSTRUCCION MEDIANERAS}

Los apeos se refieren a edificios con muros de carga que son colindantes a la obra que se va a realizar. EI supuesto más normal es que no tengan sótano y que el de nueva planta sí lo tenga.

La medida primordial es la inspección de las paredes obteniendo fotografías de los desperfectos y tomando plomadas de las paredes. En el derribo conviene dejar el muro propio que está adosado y algún otro que sirva de contrafuerte, especialmente en las alturas inferiores, siendo ésta la mejor manera de obtener un sostenimiento natural, aunque desgraciadamente no suelen tomarse estas precauciones.

Las paredes deben quedar limpias de materiales que puedan desprenderse, siendo conveniente aplicar en el paramento un guarnecido o enfoscado que supla la falta de cohesión de la fábrica.

\section{sostenimiento de fachada}


No puede darse una solución tipo pues depende de las condiciones de los edificios. Puede acarrear peligro si las paredes corresponden a dependencias que alojen servicios, pues los muros suelen ser débiles y con precaria sujeción, ocurriendo lo mismo en los casos en que los muros tengan falta de trabazón o se encuen-

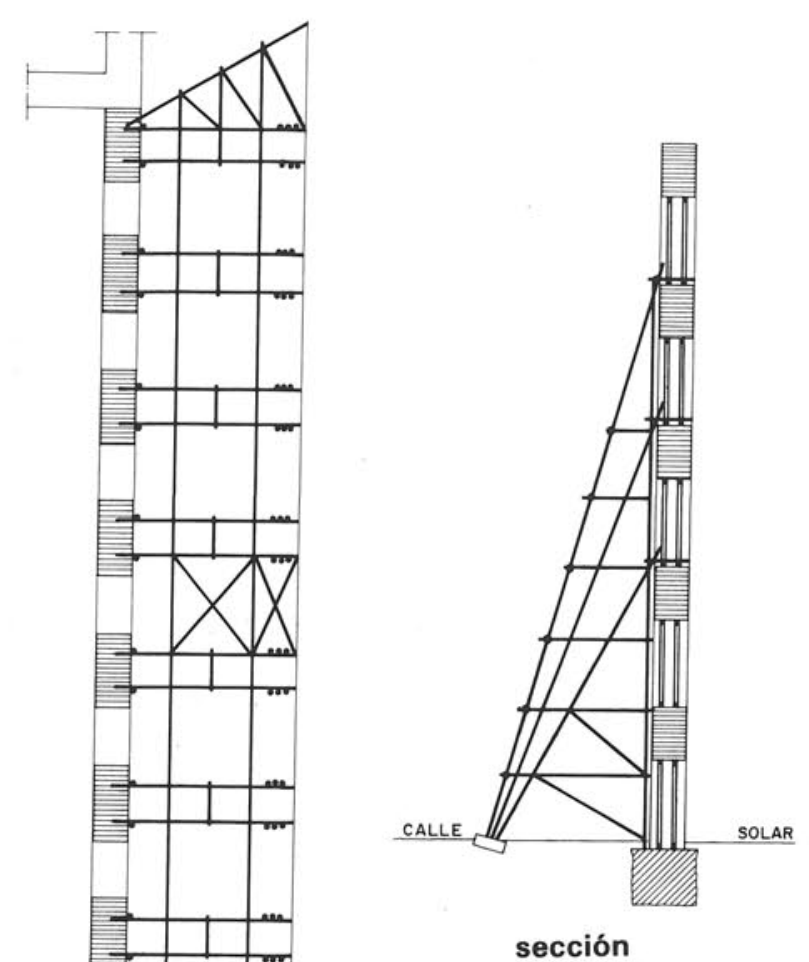

planta

\section{sostenimiento de fachada}

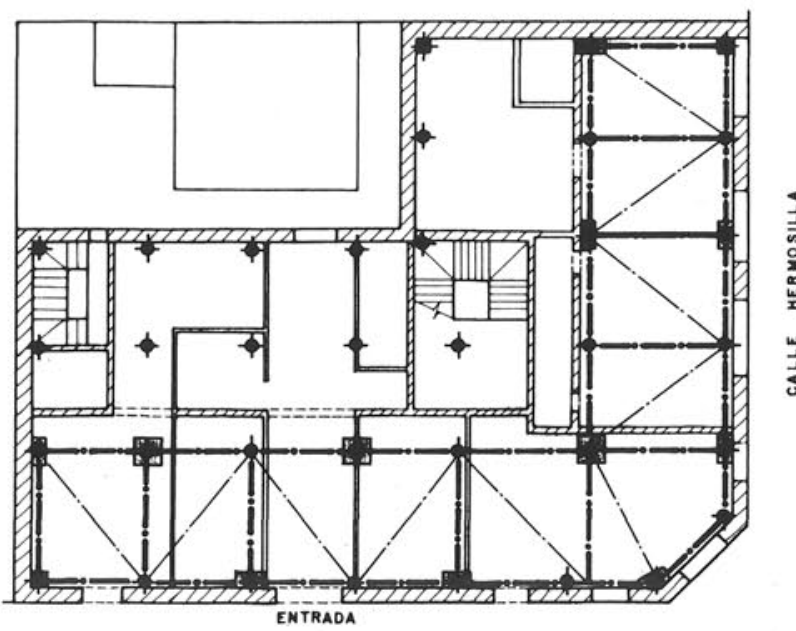

planta tren separadoś en los interiores. Cuando los edificios son estrechos precisan de unas precauciones especiales. La densidad y robustez del apeo es dependiente de estas circunstancias.

De precisarse el apeo y si hubiera edificios situados a ambos lados del solar, lo eficaz es acodalar ambos. Si la distancia entre ellos fuera superior a los 20 metros convendría colocar un pie intermedio que acortara la luz, apoyándolo en el nivel del último sótano mediante el correspondiente pozo. En caso de edificio a un solo lado el apuntalamiento debe ser inclinado hacia el interior del solar. Si fueran tres lados los ocupados por medianeros los acodalamientos son más fáciles.

Es suficiente con que los acodalamientos se hagan cada tres alturas coincidiendo con los forjados, distanciados horizontalmente unos 12 metros y como mínimo en dos puntos.

Respecto al apeo, es conveniente hacerlo metálico, con perfiles comerciales o tubos, bien por suministro propio o por el sistema de alquiler. Es favorable utilizar elementos flexibles en formación de celosía. Los elementos rígidos pueden dañar el edificio como consecuencia de la dilatación térmica.

El contacto entre los codales y el edificio se hace por intermedio de tablones de madera, procurando se canalice su transmisión por forjados y llevando apoyos en vertical por la pared.

Por lo general, un codal que repercuta en unos $120 \mathrm{~m}^{2}$ (cada 3 alturas y separado en horizontal $12 \mathrm{~m}$ ) es suficiente se proyecte para 4 ó 6 t. A título orientativo, un tubo de diámetro $48 \mathrm{~mm}$ admite una carga de 1 a 1,5 t en longitud de 3 metros. Es por tanto un esfuerzo razonable y menor a lo que generalmente se estima. Es preferible un apeo ligero, correctamente concebido, a otro de mayor entidad, defectuosamente situado o colocado.

No son excepciones los edificios que no pueden ser derribados por entrañar un serio riesgo para los colindantes. Varios de ellos, que componen una manzana, pueden hallarse acodalados entre sí y la carencia de estabilidad individual es suplida y favorecida por el conjunto. El recurso es hacer una estructura interior para la nueva arquitectura, que permita la demolición posterior de lo actual. El derribo en principio sería limitativo a los elementos ornamentales, de instalaciones, entrevigados y otros de menor importancia que no sean resistentes.

\section{PROBLEMAS ADMINISTRATIVOS QUE SE PRESENTAN AL ABORDAR LAS REPARACIONES O RECONSTRUCCIONES}

Expresados de manera sucinta, pensamos que los problemas son:

\section{a) Financiación}

Es posible se arbitren fórmulas de financiación por parte de la Administración para que los pisos de 
Informes de la Construcción/338

alquiler puedan ser adquiridos por los ocupantes, lo que permitiría opción a la reparación.

b) Mentalización de los ocupantes

Los nuevos ocupantes-propietarios necesitan convencerse de la gravedad de la situación y de que, por sus propios intereses, debe procederse a las consolidaciones que sean ineludibles. Es un tema difícil y posiblemente requiera la participación legal que obligue en casos extremos.

\section{c) Soluciones técnicas}

Las soluciones técnicas deben ser oportunas y eficaces, acompañadas de un programa escalonado con presupuesto, plazo y otros condicionamientos. Un conocimiento no acertado o falto de experiencia en su aplicación puede producir desvíos importantes en perjuicio de los interesados.

d) Actitud de las autoridades competentes

Es trascendental su papel en estos temas. Por una parte, parece buena la exigencia de no autorizar cambios de fisonomías en las edificaciones afectadas por los planes especiales, obligando a la rehabilitación o en todo caso a la conservación de la fachada, pero no parece acertado llevar su exigencia mucho más allá de ciertos límites, pues difícilmente se encontrarán Sociedades dispues-

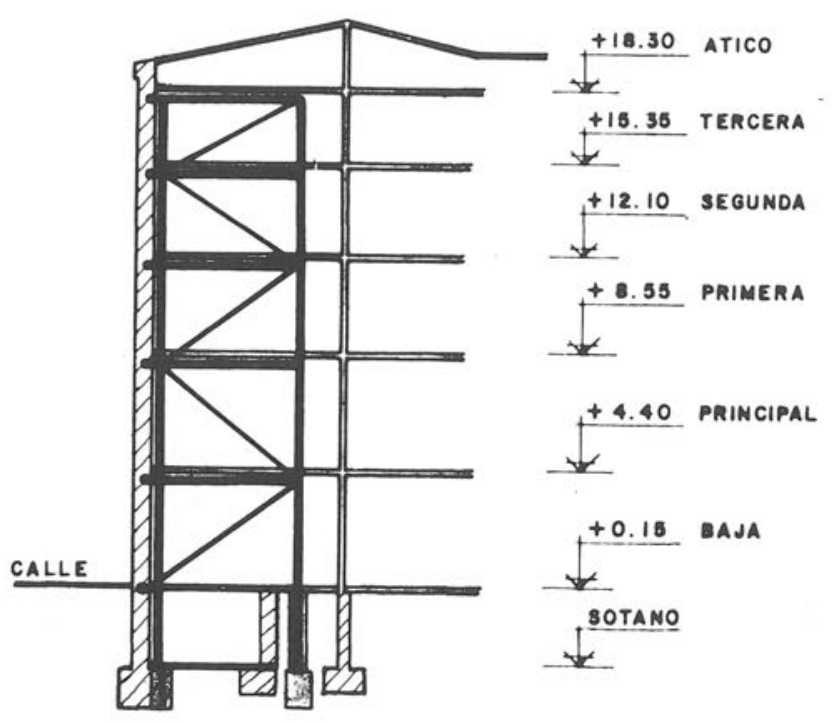

tas a hacer obras que no puedan ser rentables o rayen en el altruismo. Por otra parte, quizá pequen al inhibirse en la no consenvación de los inmuebles, bien por falta de medidas legales o por razones sociales.

El desconocimiento estadístico del estado resistente de los inmuebles antiguos viene a ocultar la gravedad en que se hallan la mayor parte de ellos.

\section{publicación del i.e.t. c.c.}

\section{las resinas epoxi en la construcción}

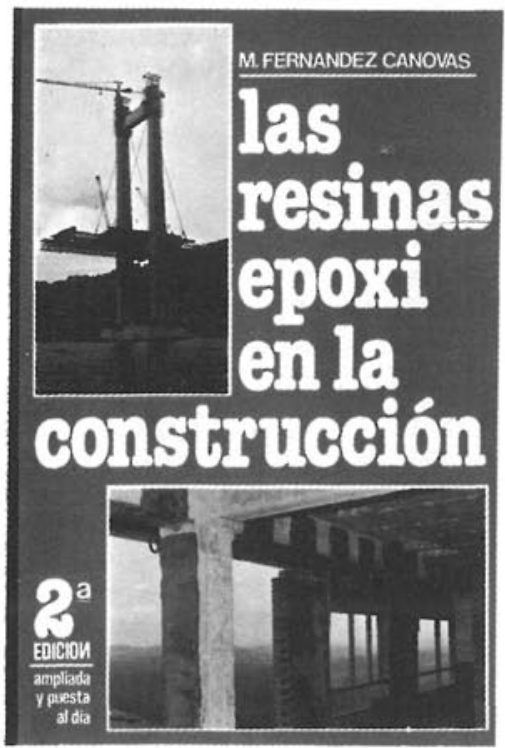

Manuel Fernández Cánovas

Dr. Ingeniero de Construcción

Este libro, el primero en lengua castellana sobre resinas epoxi aplicadas a la construcción, está dirigido a arqui Este libro, el primero en lengua castellana sobre resinas epoxi aplicadas a la construcción, está dirigido a arquitoda una extensa gama de aplicaciones de gran interés.

El autor trabaja desde hace muchos años en el campo de la investigación, especialmente en el estudio de refuerzos y reparaciones estructurales realizados con resinas epoxi.

Con un lenguaje sencillo se tocan todos los problemas que pueden presentarse en la construcción y en los que la solución puede radicar en el correcto empleo de las resinas epoxi.

Se estudian los componentes de las formulaciones epoxi, sus propiedades fisicas y quimicas, y aplicaciones, deteniéndose, detalladamente, en las siguientes:

Unión de hormigón fresco a hormigón endurecido. - Unión de hormigones entre si. - Inyecciones de fisuras y grietas. - Unión de acero a hormigón. - Barnices y pinturas. - Las combinaciones brea-epoxi. - Revestimientos de
depositos alimenticios. - Sellado de superficies cerámicas. - Protección de tubos. - Los suelos epoxi en sus diferentes variantes. - Terrazo epoxi.-Reparación de baches. - Reparación de desperfectos en estructuras. - Reparación res variantes. - Terrazo ipox. - Runtas elásticas. - Guardacantos de tableros de puentes, - Refuerzos de pilares. vigas, forjados y zapatas, etc. - Consolidación de suelos. - Anclajes. - Protección de aceros en pretensado.

Se termina con unos capitulos dedicados a la limpieza y preparación de las superficies según los materiales a unir al control del estado superficial de èstos; a las condiciones de temperatura de aplicación; limpieza de los útiles de trabajo; precauciones en el manejo de los sistemas; almacenaje, mezcla y manejo de las formulaciones epoxi métodos de ensayo de sistemas y aplicaciones epoxidicas.

Un volumen encuadernado en cartoné plastificado con lomo de tela, de $17 \times 24 \mathrm{~cm}$, compuesto de 334 páginas y 158 figuras y fotografias.

Madrid. 1981.

Precios: España, 1.700 ptas.; extranjero, S USA 24.00 


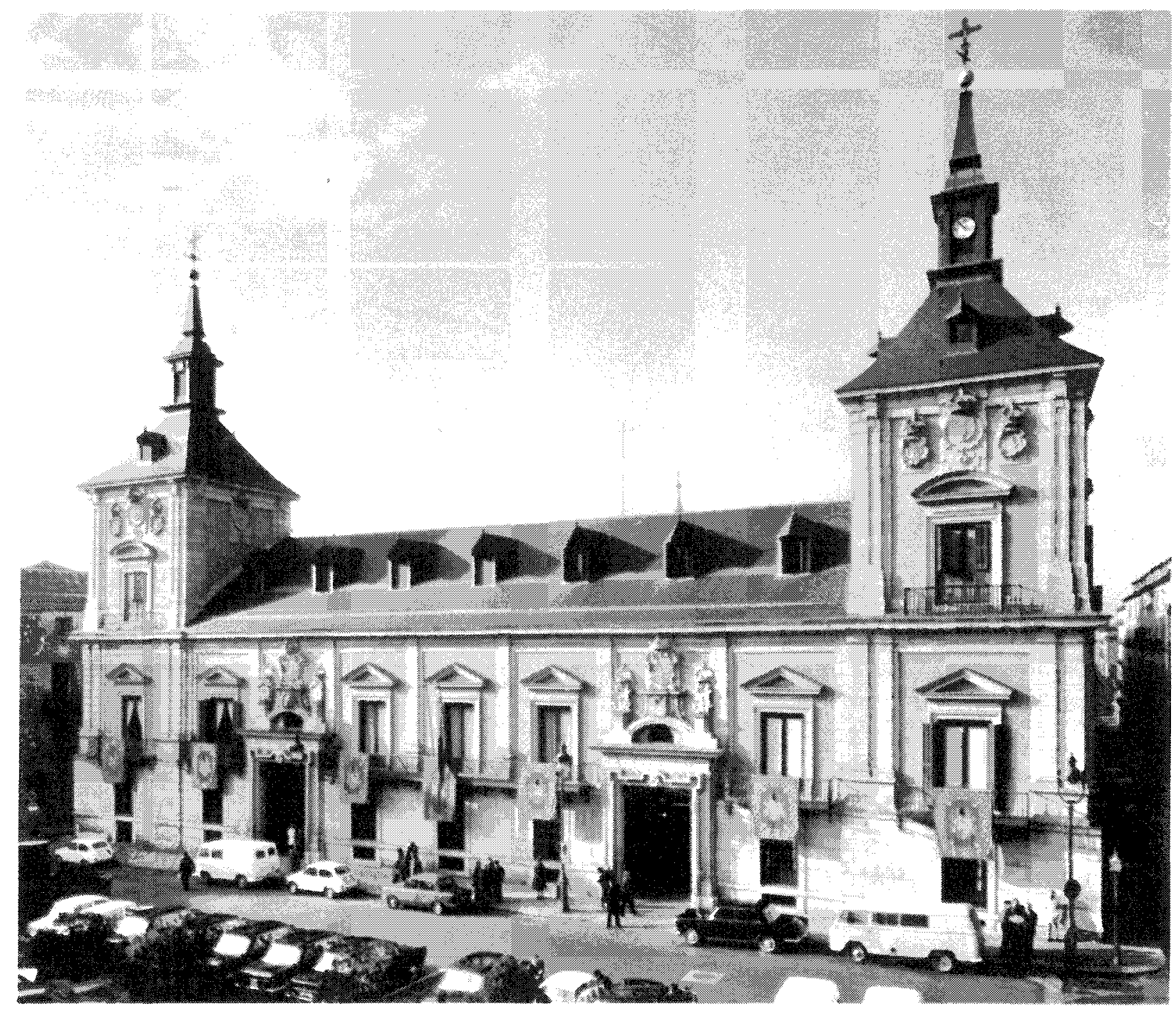

Primera Casa Consistorial, Madrid.

\section{CONSTRUCCIONES AMGEL B. BELTRAN, S. A.}

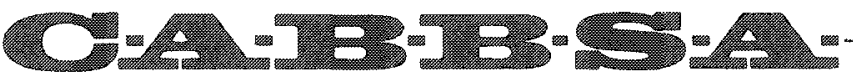

\section{División: Restauración de monumentos}

Salón de Goya, Ayuntamiento de Madrid.

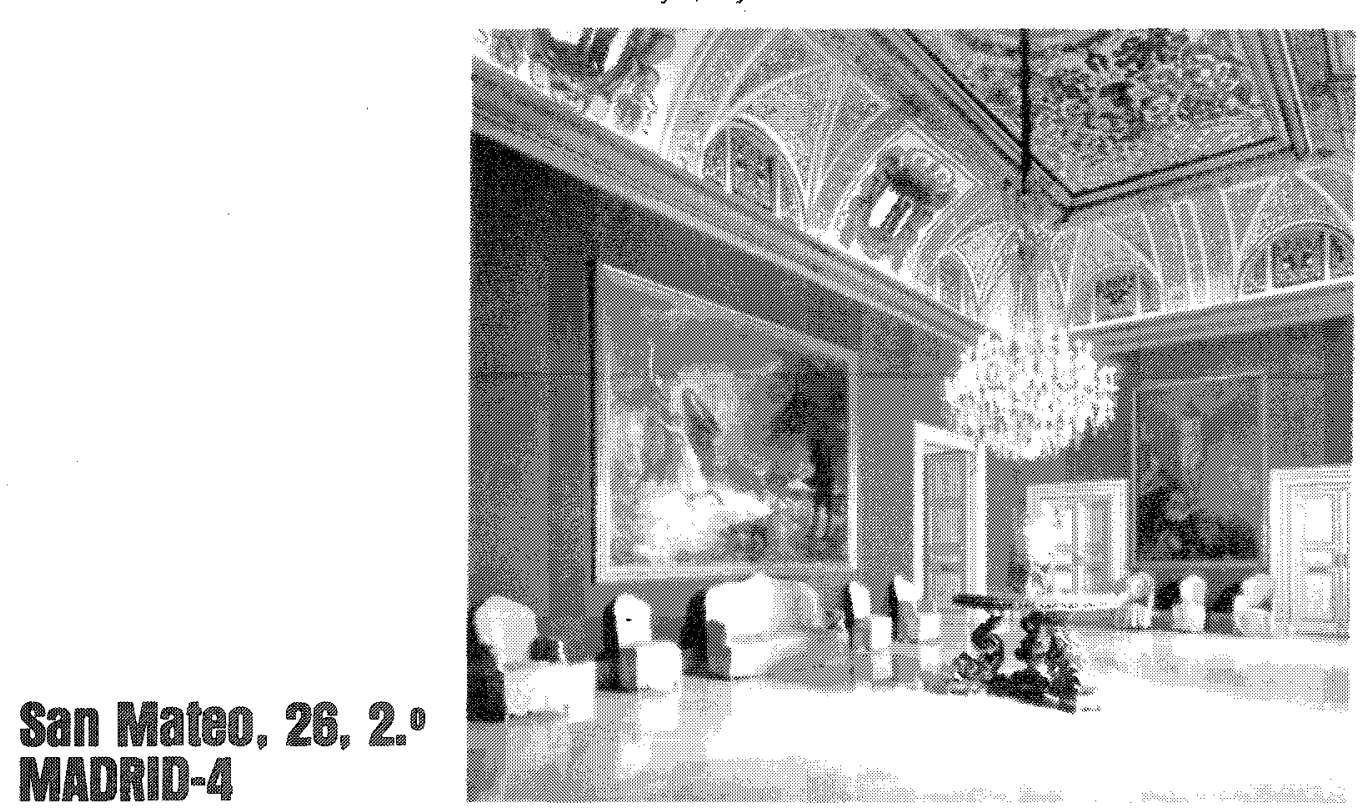

Telâlonos: 41937 66-419 3968 


\section{RESTAURACION Y REVITALIZACION DEL CUARTEL DEL CONDE DUQUE, ENMADRID (ESPAÑA)}

La actuación promovida por el Ayuntamiento de Madrid sobre el Cuartel del Conde Duque, dirigida a su recuperación estética y funcional, adaptado a los nuevos usos programados, representa para la ciudad el hecho de mayor relevancia de intervención no especulativa sobre un elemento muy representativo del austero y castizo barroco madrileño.

La posición verdaderamente clave dentro de la estructura urbana de la villa y en concreto de su centro histórico, su intrínseco valor dentro de la escena del barrio, unido a la gran superficie que ocupa -superior a una hectárea - han particularizado en su caso el «ser o no ser» de la posibilidad de recuperar para la ciudad y sus ciudadanos un espacio de encuentro ampliamente reivindicado por las Asociaciones de Vecinos, frente a las ambiciones mercantiles de las inmobiliarias que apoyadas en envejecidos plantea-

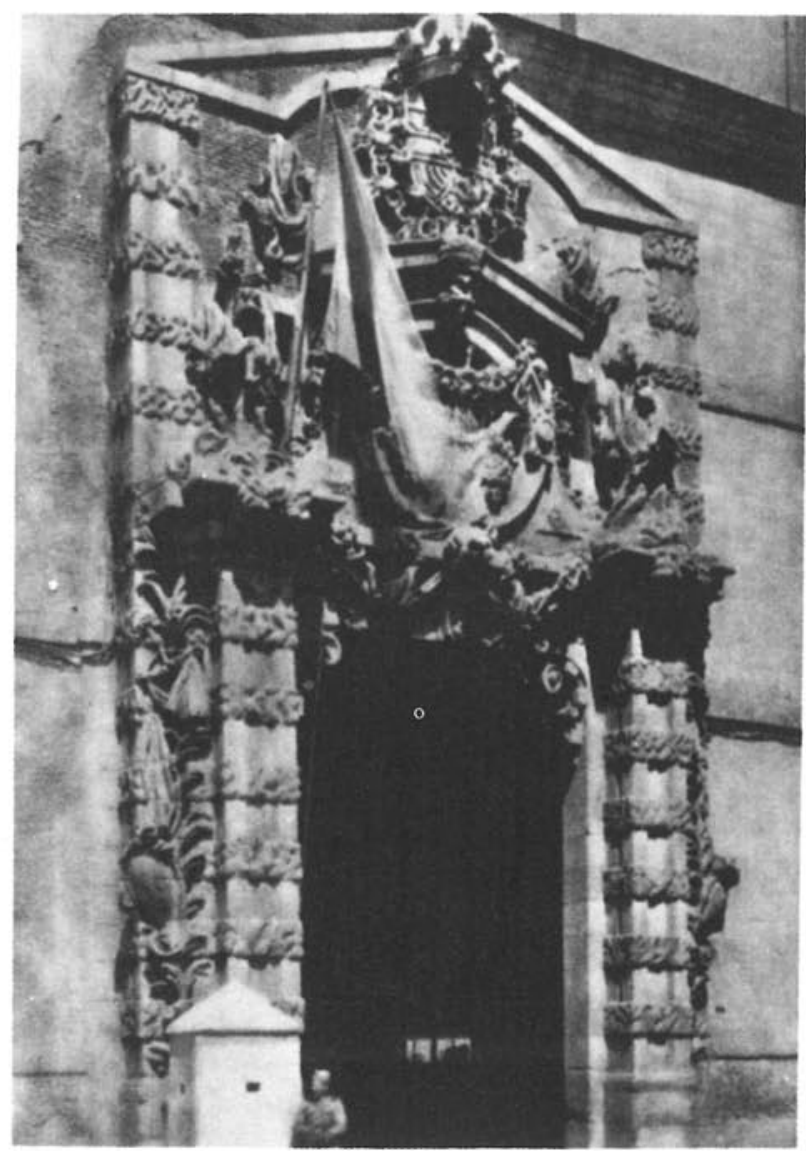

Portada del Cuartel del Conde Duque

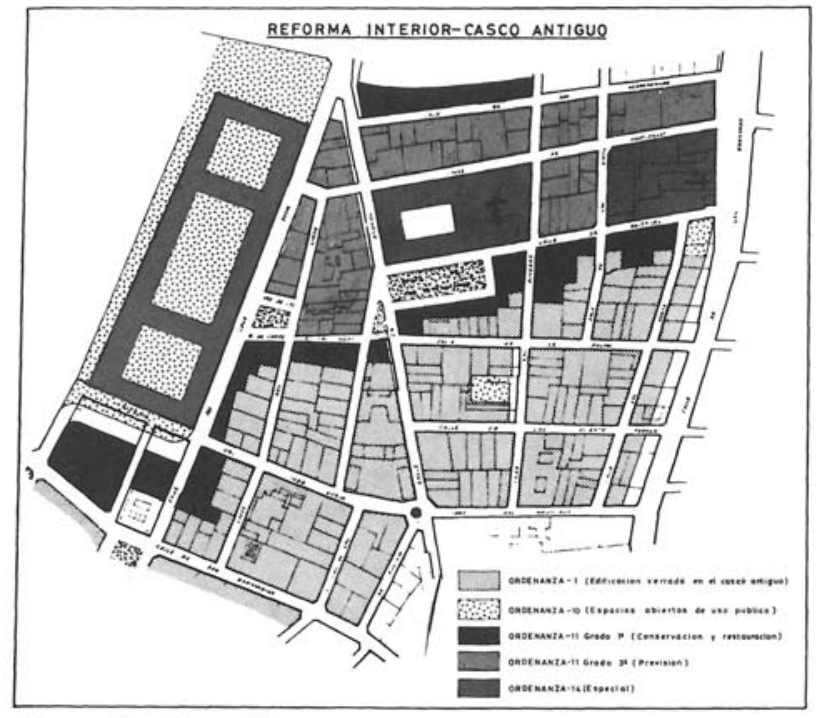

Plano de situación

mientos de remodelación urbana plasmados en planes urbanísticos municipales, vieron el gran negocio que representaba la obtención de suelo urbano, de carácter especulativo, en condiciones muy ventajosas.

La proyectada Gran Vía Diagonal ha sido la espada de Damocles de la zona durante años, en lo que representaba la concepción gigantista del Gran Madrid de la postguerra.

El «Plan Malasaña» pretendió la remodelación del barrio vecino a Conde Duque y supuso, de forma colateral, una nueva amenaza del empleo de la «piqueta» como técnica de intervención urbana que ya había actuado, de forma contundente, en otras parcelas de la ciudad, en una confrontación desigual en la que la capacidad de respuesta del ciudadano y del vecino eran prácticamente nulas; el barrio de Pozas, Buen Suceso, Jareños, Olavide, Parque de Bomberos de O'Donnell, etcétera, están aún en la memoria de todos, por representar espacios y ambientes sociales $e$ históricamente significativos, que sucumbieron ante un concepto urbano en el que determinados intereses individuales prevalecieron sobre un concepto social de la ciudad, $o$ ante planteamientos paisajísticos urbanos irrespetuosos con la esencia y personalidad de Madrid.

El «indulto» para la amenaza de su desaparición fisica, que no para frenar el proceso de deterioro que sufría, el Cuartel del Conde Duque lo representa su compra por el Ayuntamiento de Madrid al Ministerio del Ejército, en 1969, con el expreso compromiso de mantener el volumen edificado existente, devolverle su antiguo trazado y restaurarlo de acuerdo con el proyecto original. 


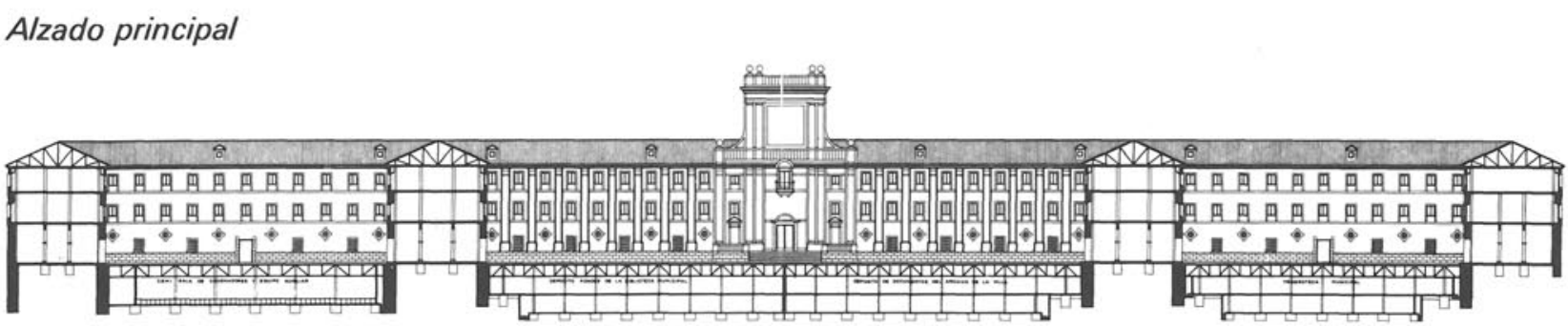

Sección

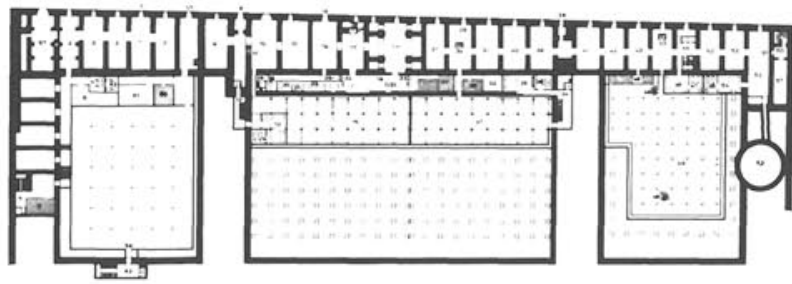

Planta sótano (nivel inferior)

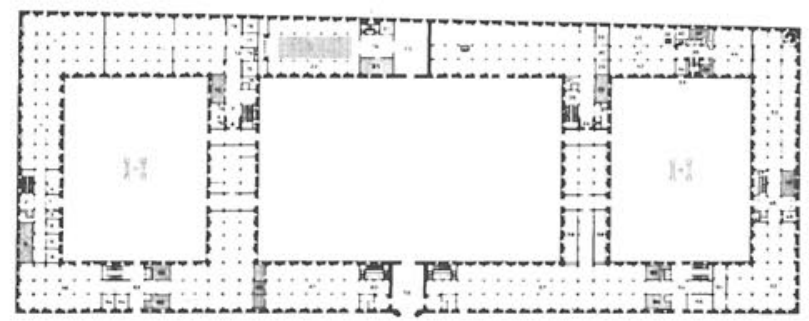

Planta baja

Durante la alcaldía de Arias Navarro se redacta el «Plan Parcial de los Cuarteles del Conde Duque y su entorno», englobado en el "Plan Parcial de Reforma Interior del Casco Antiguo» que fue aprobado en 1969 por COPLACO, con la intención de restaurarlo y dotarlo de un uso público que incluía los jardines del Palacio de Liria; este objetivo no se alcanzó y el edificio fue destinado parcialmente como Delegación Municipal de Tráfico durante años, sin que se planteara ninguna actuación que impidiera su progresiva destrucción; en 1976 fue declarado Monumento Nacional.

\section{Su historia}

Se debió su concepción y realización a Pedro de Ribera, arquitecto (Madrid, 1683 - M. 1742), en 1720, como cuartel de la Real Guardia de Corps de Fe- lipe $V$, a iniciativa del Marqués de Vadillo - Maestro Mayor del Ayuntamiento de Madrid (1726-1729) y sucesor de Ardemans en el puesto-. Fue también autor, entre otras, de las siguientes obras: fachada de la Iglesia de Montserrat; reparación del puente de Toledo; Hospicio de San Fernando (hoy Museo y Biblioteca Municipal); iglesias de San Cayetano, de San José para el Carmen descalzo y de San Antón; Palacio de los Duques de Santoña (hoy Cámara de Comercio); Palacio de Miraflores; portada del palacio del Marqués de Perales, y parque de la Virgen del Puerto.

El edificio de los Cuarteles del Conde Duque (financiado por el pueblo madrileño a través de un impuesto especial que gravaba el aceite, cacao y azúcar) tiene forma rectangular $(270 \times 75 \mathrm{~m}$, aproximadamente $) e$ incluye tres patios interiores, más amplio el central, con altura de tres plantas y un sótano. En 1869 sufrió un voraz incendio que destruyó la torre de la capilla $y$ las cubiertas originales.

\section{Intervención actual}

La actuación sobre el edificio se encuadra dentro de la denominada "rehabilitación ligera», con objeto de recuperar las condiciones de habitabilidad y adecuación de los espacios a las nuevas necesidades planteadas, poniendo al descubierto los valores espaciales sin modificar su concepción original en otra antagónica del proceso expropiación-derribo-nueva adecuación y reedificación.

El planteamiento restaurador respeta la arquitectura original que se concreta, de una forma más expresiva, en la realización de las fachadas; gran predominio de los enfoscados; combinación de contraste de colores entre los paramentos, y los recercados y antepechos de los huecos. Se mantienen las pilastras de granito en las plantas bajas y en las arquerías de ladrillo que soportaban el forjado original, de gran interés.

El edificio tiene un marcado carácter cultural y comunitario, dedicado a: Hemeroteca y Biblioteca Municipal, Instituto Arqueológico, Archivo de la Villa y Centro Informático y de Proceso de Datos del Ayuntamiento. El proyecto se divide en varias fases, consis- 
Informes de la Construcción/338

tiendo la primera en la creación de la Hemeroteca y las Salas de Exposiciones, donde ya se han realizado recientemente la presentación del Avance del Plan General de Madrid, y una exposición sobre Remodelación urbana en Europa, en marco realmente adecuado.

La escasez de espacio para alojar el completo programa de necesidades, con visión de futuro, ha obligado al vaciado de los patios, donde se alojarán los servicios que requieren volúmenes importantes.

Madrid recupera, de esta forma, una de sus señas de identidad más importantes, que puede servir como ejemplo de una política de restauración urbana y arquitectónica que no, por puntual, deja de ser menos valiosa, y si se parte de la base de considerar que la ciudad "ya está hecha», en lo que representa de realidad no cuestionable, tal vez manifiesta la única forma de intervención que garantiza, como suma de actuaciones parciales - base de un planteamiento globalla conservación de lo que de valioso nos legó el pasado

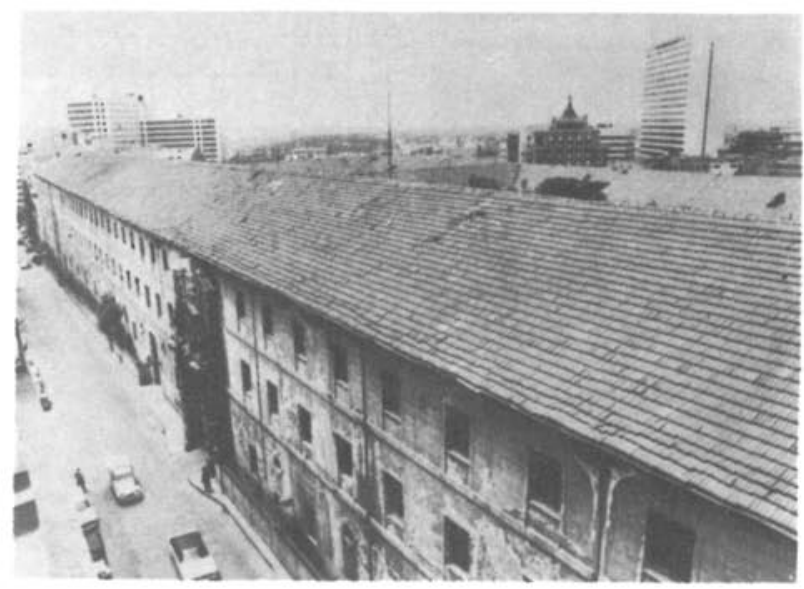

Estado de la fachada antes de la remodelación

y debemos conservar, a la vez que nos sirve de escenario, espacio de convivencia, lugar de encuentro $y$ acceso a la cultura.

P.D.R.

\section{última publicación del i.e.t.c.c.}

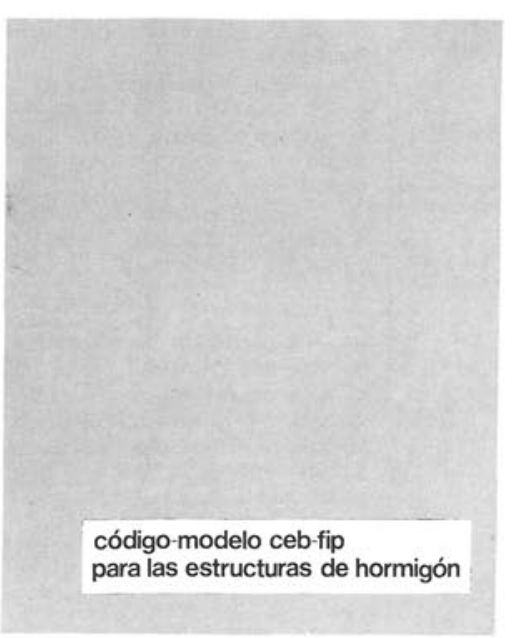

\section{CODIGO MODELO CEB.FIP PARA LAS ESTRUCTURAS DE HORMIGON}

El Instituto Eduardo Torroja, miembro activo tanto del Comité Eurointernacional del Hormigón (CEB), como de la Federación Internacional del Pretensado (FIP), ha tomado a su cargo la traducción y edición de esta importante normativa

Aunque presentado con el titulo de "Código Modelo CEB/FIP 1978" este documento incorpora los dos primeros volúmenes de este «Sistema Unificado Internacional de Reglamentación Técnica de Ingenieria Civils. El primer volumen de este "Sistema Unificado" es el denominado "Reglas comunes Unificadas para los diferentes tipos de obras y materialesn, donde se exponen los criterios y formatos de seguridad a que han de ajustarse los diferentes Códigos (estructuras de hormigón, estructuras metálicas, estructuras mixtas, estructuras de albañileria y estructuras de madera), que han de configurar la totalidad del antedicho sistema.

El segundo volumen es propiamente el Código Modelo para las Estructuras de Hormigón. Fruto de la colaboración de dos asociaciones del prestigio del CEB y la FIP, desde mediados de los 60, incorpora los avances científicos y tecnológicos producidos en los últimos años sin detrimento alguno de la claridad y operatividad que deben presidir un código que pretende ser, ante todo, un auxiliar práctico para los técnicos de la construcción.

El Código sigue en su estructura las reglas más o menos clásicas: una primera parte dedicada a los datos generales para el cálculo (propiedades de los materiales, datos relativos al pretensado, tolerancias); en segundo

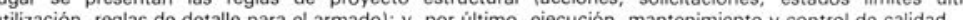

También incluye reglas para estructuras con elementos prefabricados y estructuras de hormigón con áridos ligeros. Los Anejos del Código se refieren a: terminologia, proyecto mediante la experimentación, resistencia al fuego, ecnologia del hormigón, comportamiento en el tiempo del hormigón y fatiga.

Un volumen encuadernado en cartoné, de $21 \times 30 \mathrm{~cm}$, compuesto de 340 páginas, Madrid, mayo 1982

Precios: España 2.500 ptas. Extranjero 36 \$ USA. 

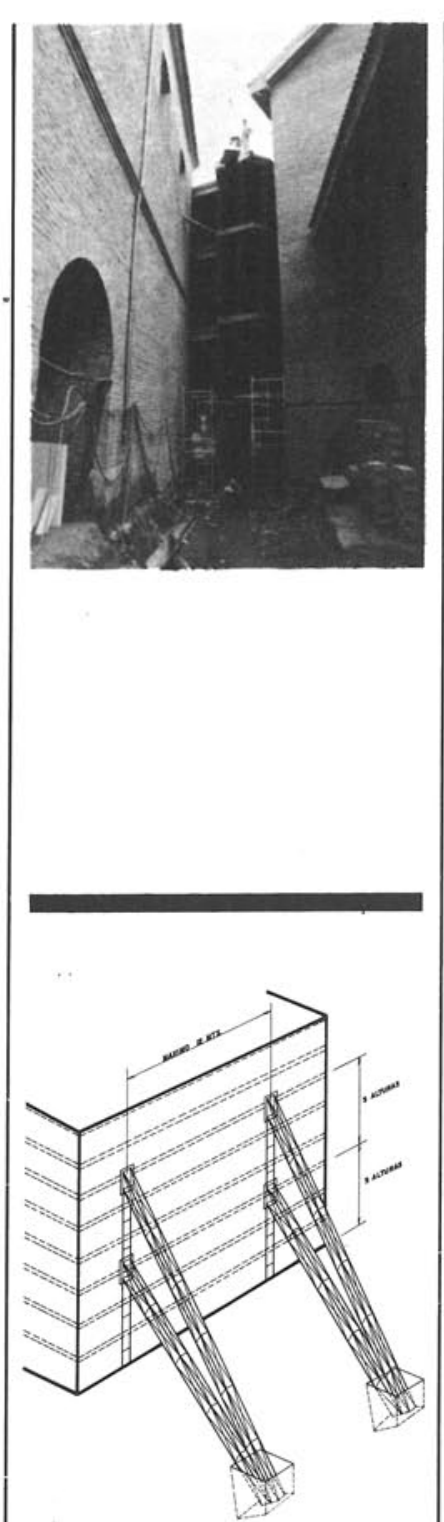

\section{Résumés \\ Ensemble résidentiel, commercial et de bureaux "Las Francesas" Valladolid - Espagne Bureau LAMELA \\ Summaries \\ Residential, commercial and office complex «Las Francesas" \\ Valladolid/Spain \\ Estudio LAMELA}

Ouvrage situé en ville, encadré dans l'enceinte ancienne, avec des édifices monumentaux à l'intérieur.

Reconstruction et ravalement des monuments, dont le caractère fonctionnel permet leur intégration dans l'ensemble et la vie urbaine quotidienne.

L'architecture actuelle, d'une sobriété recherchée, sert de cadre pour renforcer le caractère fonctionnel et visuel des monuments.

Restitution et

transformation structurale des bâtiments anciens

Rafael Buzón.

ingénieur des Ponts et Chaussées

\section{OTEP INTERNACIONAL}

Les règlements municipaux de la plupart des villes exigent que les bâtiments ayant un certain caractère traditionnel ou histo rique soient respectés et qu'ils soient restitués ou reconstruits pourvu que leurs façades soient complètement conservées ave leur même aspect architectural.

Un pourcentage important du volume futur de construction sera réservé à cette sorte de bâtiments.

Des quartiers complets bátis a une même époque, avec des caractéristiques constructives similaires, sont au même degré de détérioration ou de vieillissement dô au cours des ans. Leur état résistant est précaire, ce qui exige une prompte restitution si l'on veut éviter le délogement massif et la perte irréversible des immeubles.

Il faut donc connaitre la technique utilisée, le comportement des matériaux, les dommages habituels les plus fréquents ou ceux qui sont dus au vieillissement et la méthode efficace pour aborder les problemes de re la cons truction.
A project in a town, within the old town limits, with monumental buildings inside.

Reconstruction and restoration of the monurnents, included in the complex and in daily town life, by giving them a purpose.

The present architecture, deliberately sober, serves as a frame to enhance the function and appearance of the monuments.

\section{Rehabilitation and}

structural reform of old buildings

Rafael Buzon, Road Engineer OTEP INTERNATIONAL

Council Ordinances in most towns require traditional or historical buildings to be respected by rehabilitating or rebuilding them, with the obligation of preserving the whole facades in their original architectonic appearance.

An important percentage of the future volume of building will future volume of building will
be concerned with these buildbe conct
ings.

Entire districts built at the same period, with similar building characteristics, are in the same degree of deterioration or ageing caused by the years, with a precarious resistant state, and need prompt rehabilitation if massive loss of these buildings are to be avoided.

It is necessary to know the technique used, the behaviour of the materials, the most frequent damages caused by vice or ageing and the most efficient form of repair to approach this forgotten sphere of construction. dislodging and the irreversible
Zusammenfassungen

Wohn-, Geschäfts- und Bürokomplex

"Las Francesas"

Valladolid/Spanien

Studio LAMELA

Ein Bau in einem Abschnitt der Altstadt mit monumentalen Gebäuden innerhalb seiner Grenzen.

Wiederherstellung und Restauration der Denkmäler, die sich durch ihre Funktionalität dem Komplex und dem Stadtleben anpassen.

Die derzeitige Architektur dient in ihrer bewusste gesuchten Strenge als Rahmen, um die Monumente sowohl, in ihrer Funktion als auch in ihrem Funktion als auch
Aussehen zu kräftigen.

Wiederherrichtung und strukturelle Reform alter Gebäude

Rafael Buzón, Ingenieur OTEP INTERNACIONAL

Die Verordnungen der meisten Städte fordern heutzutage, dass den Bauten, welche einen gewissen traditionellen oder historischen Charakter besitzen, Respekt entgegengebracht wird. Diese sollen zwangsläufig so wiederhergerichtet oder aufgebaut werden, dass die Fassade in architektonischer Hinsicht insgesamt erhalten bleibt.

Ein bedeutender Prozentsatz des zukünftigen Bauvolumens wird sich diesen Gebäuden zuwenden.

Ganze Bezirke, die in der gleichen Epoche errichtet wurden und ähnliche Baumerkmale aufweisen, befinden sich auf Grund der verstrichenen Jahre in einem Zustand, der auf Zerstörung oder Alterung, auf Widerstandstän, au mangelnde Widerstandsfahigkeit usw. hinweist. Eine baldige Wiederherrichtung dieser $\mathrm{Ge}$ bäude ist unbedingt erforderlich, soweit ein massives Ausziehen der Bewohner und der nich wiedergutzumachende dieser Bauten vermieden werden soll.

Um sich diesem vergessenen Bereich des Bauwesens widmen zu können ist es erforderlich, die angewandte Technik, das Materialverhalten, die Häuligsten Schäden auf Grund der Alterung sowie die wirksamsten Reparaturmassnahmen zu kennen. 